\title{
Insertion polymorphism of retrotransposable elements in populations of the insular, endemic species Drosophila madeirensis
}

\author{
D. LEPETIT, * A. BREHMt, P. FOUILLET* and C. BIÉMONT* \\ *UMR CNRS. 5558: Biométrie et Biologie Evolutive, Université Lyon 1, 69622 Villeurbanne Cedex, France, +Center of Biological \\ Sciences, University of Madeira, Campus of Penteada, 9000 Funchal, Portugal
}

\begin{abstract}
The insertion site numbers of the retrotransposable elements (TE) 412, gypsy and bilbo were determined in individuals of five distinct natural populations of the endemic species Drosophila madeirensis from the island of Madeira. The TE distributions were compared to those of the paleartic, widespread and phylogenetically closely related species, $D$. subobscura. In situ hybridization and Southern blots showed that in D. madeirensis the number of insertion sites ranged between 10 and 15, three and six, and 35 and 42 for elements 412, gypsy and bilbo, respectively. The corresponding values for $D$. subobscura were similar. Two of these elements, 412 and gypsy, had very few insertions in the heterochromatin, unlike bilbo, which displayed a high heterochromatic insertion number. The Southern band polymorphism was very high, leading to within-population variation of $97.2 \%$, whatever the population and the TE concerned. Using the polymorphic TE insertion sites as markers to analyse population structure by AMOVA, adapted for RAPD (Randomly Amplified Polymorphic DNA) data, we found small but significant genetic differences between the populations on Madeira. This slight differentiation, coupled with similar copy numbers for each TE between populations, suggests that the $D$. madeirensis species consists of a single, only slightly subdivided population. These data also show that insular populations and endemic species of Drosophila can have as many copies of TEs as more widespread species.
\end{abstract}

Keywords: 412, bilbo, gypsy, Drosophila madeirensis, population structuring, transposable elements

Received 21 September 2001; revision received 23 November 2001; accepted 23 November 2001

\section{Introduction}

Transposable elements (TEs) are ubiquitous elements that have been found in a variety of organisms including bacteria, arthropods, plants and vertebrates. However, the way they invade genomes, populations and species is still a matter of lively debate. To understand the dynamics of these TEs, we need data about their copy numbers and genomic localization in different species. Although data on TE genomic distributions are now available for various organisms, including plants (Heslop-Harrison et al. 1997) and mammals (Löwer et al. 1996; Patience et al. 1997), most of what we know comes from Drosophila, and especially from D. melanogaster (Biémont \& Cizeron 1999). However, this may not reveal the whole story. For example,

Correspondence: Christian Biémont. Fax: (33) 4788927 19; E-mail: biemont@biomserv.univ-lyon1.fr
D. simulans has an unusually low average chromosomal insertion site number per genome for many TEs (Vieira et al. 1999). Similarly, D. algonquin and D. affinis are characterized by having a few high-copy-number elements with high occupancy (Hey 1989), whereas in the Hawaiian Drosophila, the $L O A$ and $u h u$ elements have high insertion site numbers on the chromosome arms. The distribution of these two elements seems to be related to the time since the species appeared in the various Hawaiian islands (Brezinsky et al. 1992; Wisotzkey et al. 1997). This means that the colonization process must play an important part in the dynamics of these elements, as has been proposed for the element osvaldo in D. buzzatii (Labrador et al. 1998, 1999). It is also postulated that severe bottlenecks or small effective population size due to a restricted geographical range of the species or their ecological specialization in terms of specific fruits or habitats could be responsible for the observation of fixed copies of TEs 


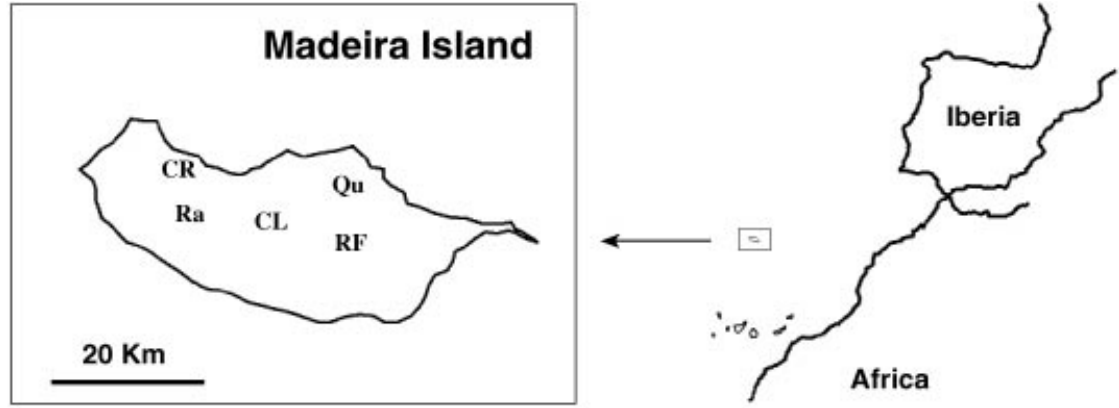

Fig. 1 Map of the island of Madeira showing the location of the five populations studied (CL, Chão dos Louros; CR, Chão da Ribeira; $Q u$, Queimadas; Ra, Rabaçal; RF, Ribeiro Frio).
(Aquadro et al. 1988), as for the mariner and 17.31 elements in D. sechellia (Capy et al. 1992; Montchamp-Moreau et al. 1993). However, D. mauritiana, an endemic species found on Mauritius, near the southeast coast of Africa, contains nearly as many copia-homologous DNA sequences as the cosmopolitan species D. melanogaster (Csink \& McDonald 1995).

The apparent unpredictability of TE behaviour from species to species may be attributable to several factors: (i) specific characteristics of the genome, which can be more or less resistant to an increase in copy number; (ii) a relationship between copy number and the distribution of the host species, a wider distribution being associated with a higher copy number, because the different environments to which the species is exposed may promote the mobilization of TEs; (iii) different species effective size; or (iv) recent mobilization or horizontal transfer of a TE in a local population, followed by the progressive invasion of the entire species. All these aspects are crucial to understanding the biology of TEs and their role in genome size variation (Tarchini et al. 2000) and population divergence (Duvernell \& Turner 1999), and also important because TEs are increasingly being used as molecular tools for phylogenetic (Sheen et al. 2000) and ecogeographic (Kalendar et al. 1999; 2000; Kumar \& Hirochika 2001) research. In the present paper, we investigate the presence and distribution of the retrotransposable elements 412, gypsy and bilbo in samples from natural populations of $D$. madeirensis, which is endemic on Madeira, and we compared their TE distribution to that of D. subobscura. In both species, we found that high TE insertion site polymorphism for 412 and gypsy was associated with high copy numbers on chromosome arms, but with few copies in the chromocentre, and with numerous copies in both the chromosomal arms and the chromocentre for bilbo. Overall, these findings suggest that species from small islands can have a high TE copy number, with high insertion-site heterozygosity despite the postulated small effective population size. Due to the great insertion polymorphism of each element found between individuals, only slight, though significant, differentiation could be demonstrated between some of the populations analysed.

\section{Materials and methods}

\section{Natural populations}

Drosophila madeirensis is an endemic species on Madeira with a habitat restricted to the Laurisilva relict Tertiary forest. The habitat of the species lies between 600 and $900 \mathrm{~m}$ altitude. Flies were collected from five, geographically distinct sites (Fig. 1), each of them situated in separate valleys or otherwise separated from each other by high mountains. The TE copy number of the flies was determined by Southern blots soon after their arrival in the laboratory. They were then maintained in the laboratory as isofemale lines with around 50 pairs every generation.

\section{In situ hybridization}

Polytene chromosome spreads from the salivary glands of third instar female larvae taken from the isofemale lines were prepared and treated with nick-translated, biotinylated DNA probes (Biémont 1994). Insertion sites were detected as brown bands resulting from a dye-coupled reaction with peroxidase substrate and diaminobenzidine.

To get a quick estimation of the TE insertion site number of the natural populations of D. madeirensis and D. subobscura, one female larva per isofemale line was analysed directly for each population. This gave us the insertion site number of diploid individuals. In addition, the insertion sites for element 412 were precisely localized on the polytene chromosomes, using the photographic maps of the sibling species D. subobscura (Brehm 1992). The names of the chromosomes and their correspondence with those of D. melanogaster are as follows: A (X); U (2 L); E (2R); J (3 L); $\mathrm{O}(3 \mathrm{R})$; and Dot (4).

The insertion site number, estimated directly using chromosomes from the larvae of isofemale lines, is sensitive to the degree of homozygosity of the individuals in the lines. Indeed, the number of insertion sites detectable in diploids by in situ hybridization decreases with increasing homozygosity (because the polytene chromosomes are composed 
of both parental homologous chromosomal sets). As a result, the in situ technique underestimates the site number of a diploid genome.

\section{Probes used}

The gypsy probe for D. madeirensis consisted of a 450-base pair (bp) polymerase chain reaction (PCR) fragment, encompassing the envelope gene (ORF3) (VasquezManrique etal. 2000). The bilbo probe was a 985-bp fragment from the 3 ' end of a D. subobscura element, encompassing a fragment between the HindIII site at position 5127 and BglI at position 6112 (Blesa \& MartinezSebastian 1997). The 412 probe from D. madeirensis was constructed by PCR amplification of a conserved region between the integrase and reverse transcriptase genes, using primers designed from the sequence of the $D$. melanogaster 412 element (Yuki et al. 1986). The primer sequences, Upp1 (5'-TTCCTTTATATGGATGACTTAATAG$3^{\prime}$ ) and Low1 (5'-TTCTATGACTTCTTTCTACTACTCC-3'), amplified a 1.8-kb fragment, which was cloned into pCR2 vector (Invitrogen ${ }^{\circledR}$ ). Flanking regions were sequenced to confirm the identity of the clone.

\section{Southern blots}

Total genomic DNA was extracted from a single female of each isofemale line by a standard phenol-chloroform method after proteinase $\mathrm{K}$ digestion. DNA was digested with EcoRI (to hybridize with the gypsy probe) or HindIII (to hybridize with both 412 and bilbo probes), which cut once within the sequences of the transposable elements. With the combination of restriction enzymes and probes, each element yields a unique band corresponding to its $3^{\prime}$ portion and a piece of the flanking genomic DNA on the autoradiographs. The number of bands on the gels therefore gave a good estimate of the number of TE complete or deleted insertions on the genome. Agarose gel electrophoresis, transfer of DNA to membranes, prehybridization, and hybridization procedures were carried out as described by Junakovic et al. (1984) and Di Franco et al. (1989). Nylon Hybond $\mathrm{N}+$ membranes (Amersham) were washed at $42^{\circ} \mathrm{C}$ in $1 \times$ saline sodium citrate and $0.1 \%$ sodium dodecyl sulphate $(3 \times 30 \mathrm{~min})$. Probes were random prime labelled with a Megaprime kit (Amersham). The X-ray film was exposed at $-80^{\circ} \mathrm{C}$ overnight or up to 4 days, with intensifying screens. The autoradiographs were scanned and the patterns were assessed with a DNA molecular weight ladder.

\section{Data analysis}

Automated detection of the bands in each individual lane on the Southern blots was done using BIO-PROFIL ${ }^{\circledR}$ image analysis software (Vilber Lourmat). This software ascribed a molecular weight to each band on the autoradiographs and made it possible to compare the gels. Assuming a 3\% error in the molecular weight of the bands, the gels were divided into 71 classes in terms of their molecular weight, with size intervals proportional to their central value. We considered only the region of the gel between 1.8 and $18.5 \mathrm{~kb}$, which could be analysed adequately. The observed bands on the gel were then ascribed to the class which included their estimated molecular weight. By assuming that DNA bands within the same molecular weight class shared the same TE sequence, all the individual profiles on the blots were scored as discrete characters using a binary matrix of 0 and 1, where 0 and 1 corresponded to the absence and presence of a given band, respectively. The data from this matrix were then analysed by molecular variance (AMOvA) based on the Euclidean distances between all pairs of profiles according to Excoffier et al. (1992), using the ARLEQUIN program (Schneider et al. 2000). The total variation was subdivided into within-population and between-population levels. The AMOVA variance components were tested for significance by nonparametric randomization tests using 1023 permutations with the null hypothesis of no population structure. To allow for the dominant nature of our TE markers, which behave like RAPD markers, we used the extended AMOvA analysis developed by Steward \& Excoffier (1996), which considers diploid populations in Hardy-Weinberg equilibrium. We thus calculated the $\Phi_{\mathrm{ST}}$ statistic, which is an analogue of the fixation index of interpopulation differentiation, $F_{\mathrm{ST}}$.

\section{Results}

\section{TE insertion site numbers on polytene chromosomes}

Table 1 summarizes the number of insertion sites of the elements 412, gypsy and bilbo per genome in the five populations of Drosophila madeirensis, estimated by in situ hybridization. Four larvae were analysed per population, and the numbers of insertion sites were determined on each chromosome arm (data not shown). The average number of euchromatic copies differed between the TEs: three to six for gypsy, 10-15 for 412 and 35-42 for bilbo, with nonsignificant differences between populations [two-way analysis of variance (ANOvA): $F=0.74, P=0.57]$. There were no significant differences between the chromosome arms for the average TE insertion site numbers for 412 $(F=2.11, P=0.09)$ and gypsy $(F=1.28, P=0.28)$. However there was a difference for bilbo $(F=17.29, P<0.001)$, which has fewer insertions on the A chromosome (average insertion site number: 4.8) than on the other chromosomes (average insertion site numbers: 6.8-10.5) (data not shown). 
Table 1 Average euchromatic insertion site number per entire genome, estimated by in situ hybridization, and mean number of bands estimated by Southern blots of the 412, bilbo and gypsy elements in five natural populations of Drosophila madeirensis

\begin{tabular}{|c|c|c|c|c|c|c|c|c|c|c|c|c|c|c|c|}
\hline \multirow[b]{3}{*}{ Technique } & \multicolumn{15}{|c|}{ Transposable elements } \\
\hline & \multicolumn{5}{|l|}{412} & \multicolumn{5}{|l|}{ bilbo } & \multicolumn{5}{|c|}{ gypsy } \\
\hline & $\mathrm{CL}$ & $\mathrm{CR}$ & $\mathrm{Qu}$ & $\mathrm{Ra}$ & $\mathrm{RF}$ & $\mathrm{CL}$ & $\mathrm{CR}$ & $\mathrm{Qu}$ & $\mathrm{Ra}$ & RF & CL & $\mathrm{CR}$ & $\mathrm{Qu}$ & $\mathrm{Ra}$ & $\mathrm{RF}$ \\
\hline $\begin{array}{l}\text { In situ } \\
\text { hybridization }\end{array}$ & $\begin{array}{l}12.5 \\
(3.1)\end{array}$ & $\begin{array}{l}15.0 \\
(2.5)\end{array}$ & $\begin{array}{l}10.8 \\
(2.2)\end{array}$ & $\begin{array}{l}12.0 \\
(5.8)\end{array}$ & $\begin{array}{l}12.5 \\
(1.3)\end{array}$ & $\begin{array}{l}35.0 \\
(5.7)\end{array}$ & $\begin{array}{l}41.3 \\
(2.6)\end{array}$ & $\begin{array}{l}41.5 \\
(7.3)\end{array}$ & $\begin{array}{l}40.3 \\
(2.5)\end{array}$ & $\begin{array}{l}38.5 \\
(8.9)\end{array}$ & $\begin{array}{l}3.8 \\
(3.2)\end{array}$ & $\begin{array}{l}3.3 \\
(1.9)\end{array}$ & $\begin{array}{l}6.0 \\
(2.2)\end{array}$ & $\begin{array}{l}3.3 \\
(2.3)\end{array}$ & $\begin{array}{l}3.5 \\
(2.1)\end{array}$ \\
\hline Southern blot & $\begin{array}{l}17.6 \\
(3.2)\end{array}$ & $\begin{array}{l}20.8 \\
(3.5)\end{array}$ & $\begin{array}{l}17.2 \\
(2.9)\end{array}$ & $\begin{array}{l}19.3 \\
(4.3)\end{array}$ & $\begin{array}{l}23.2 \\
(3.6)\end{array}$ & $\begin{array}{l}31.7 \\
(4.5)\end{array}$ & $\begin{array}{l}30.9 \\
(3.6)\end{array}$ & $\begin{array}{l}28.7 \\
(3.7)\end{array}$ & $\begin{array}{l}28.2 \\
(3.4)\end{array}$ & $\begin{array}{l}31.6 \\
(3.4)\end{array}$ & $\begin{array}{l}12.3 \\
(3.3)\end{array}$ & $\begin{array}{l}15.4 \\
(2.2)\end{array}$ & $\begin{array}{l}14.5 \\
(2.9)\end{array}$ & $\begin{array}{l}14.0 \\
(2.5)\end{array}$ & $\begin{array}{l}11.1 \\
(2.9)\end{array}$ \\
\hline
\end{tabular}

CL, Chão dos Louros; CR, Chão da Ribeira; Qu, Queimadas; Ra, Rabaçal; RF, Ribeiro Frio.

One female larva from four isofemale lines was analysed per population and TE in the in situ hybridizations. Fourteen to 18 flies were analysed per Southern blot. The standard deviation is shown in parentheses.

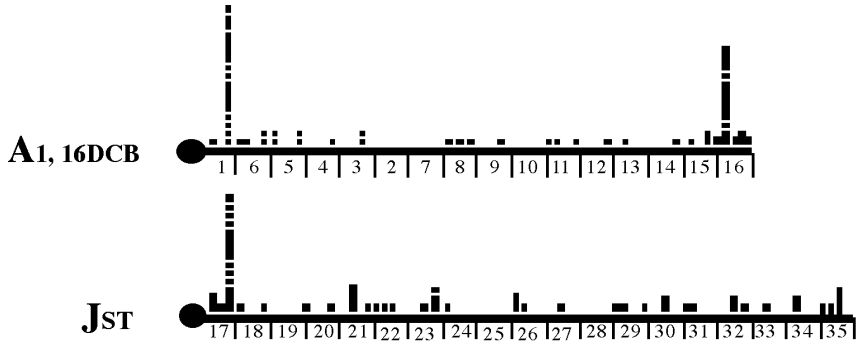

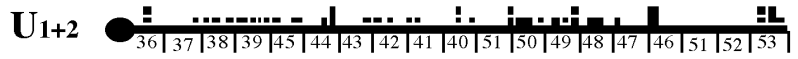

Fig. 2 Distribution of TE 412 insertions in the chromosomes of Drosophila madeirensis. Chromosome designations and divisions are according to Kunze-Muhl \& Muller (1958), modified by Brehm (1992), and display the structural arrangement of $D$. madeirensis according to Krimbas \& Loukas (1984). Black circles at the chromosome tips indicate the centromere. Squares above the chromosomes indicate the insertions. Insertions in the centromeres were found only in chromosomes $\mathrm{J}$ and $\mathrm{O}$, and are not depicted in the Figure.

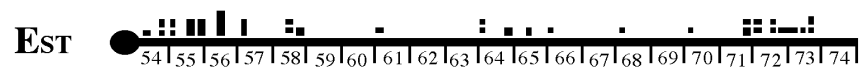

$\mathrm{O3}$

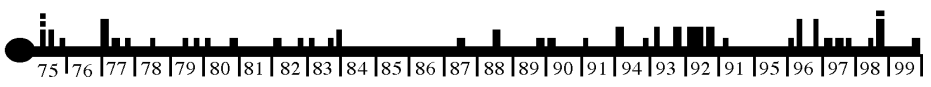

\section{Dot}

The dot chromosome only labelled for bilbo, which was also strongly labelled on the chromocentre and on the pericentromeric regions of all chromosome arms. Pericentromeric labelling was also seen at the base of chromosomes J and $\mathrm{O}$ for the 412 element. To take a closer look at insertion polymorphism, we accurately localized the 412 insertion sites on the polytene chromosomes. As shown in Fig. 2, the labelled sites were widely scattered over the chromosome arms, although there was a high frequency of insertion in sections 1 and 16 of the sex chromosome A, and in section 17 of chromosome J. Although the gypsy insertion sites were not accurately localized on the chromosomes, a close look at some in situ squashes revealed that the few labelled insertion sites were located in different chromosomal regions in different individuals and populations.
Southern profiles of D. madeirensis and D. subobscura populations

Figure 3 shows examples of Southern blot profiles of flies analysed on their arrival in the laboratory, and probed using 412, gypsy and bilbo. Table 1 summarizes the number of bands estimated from these blots in D. madeirensis. In accordance with the in situ results, different numbers of bands were found between the different TEs (ANOvA: $F=533, P<0.001$ ): bilbo had the most bands and gypsy the least, with significant differences between populations ( $F=7.85, P<0.001$ for 412; $F=6.67, P<0.001$ for gypsy; $F=3.28, P<0.05$ for bilbo). Drosophila subobscura had on average fewer bands than $D$. madeirensis for both 412 (the number of bands ranged from 5.7 to 10.6: data not shown) 


\section{D. madeirensis}
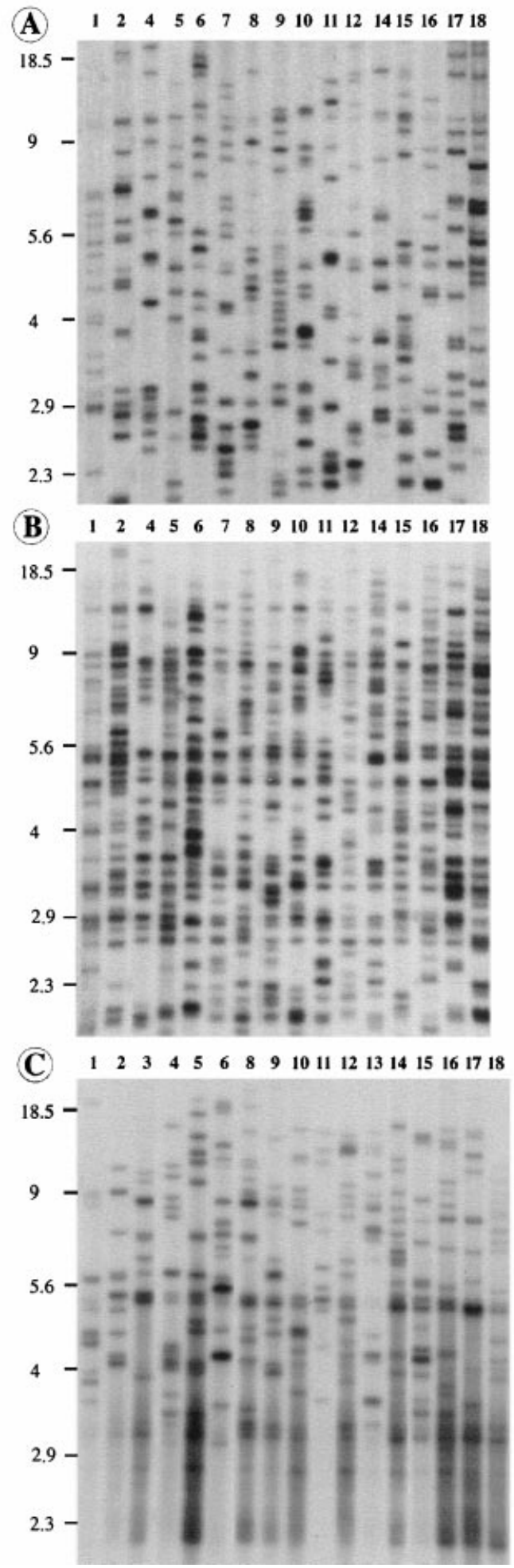

\section{D. $s$ и bо bscura}

(A) $1120 \begin{array}{lllllllllllllll} & 1 & 6 & 7 & 9 & 10 & 11 & 12 & 13 & 14 & 15 & 16 & 17 & 18\end{array}$

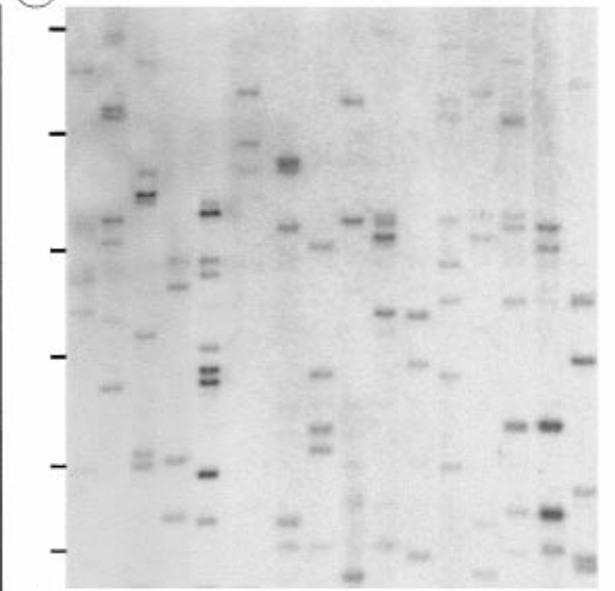

(B) $1 \begin{array}{lllllllllllllll} & 2 & 4 & 5 & 6 & 7 & 9 & 10 & 11 & 12 & 1314 & 15 & 16 & 17 & 18\end{array}$
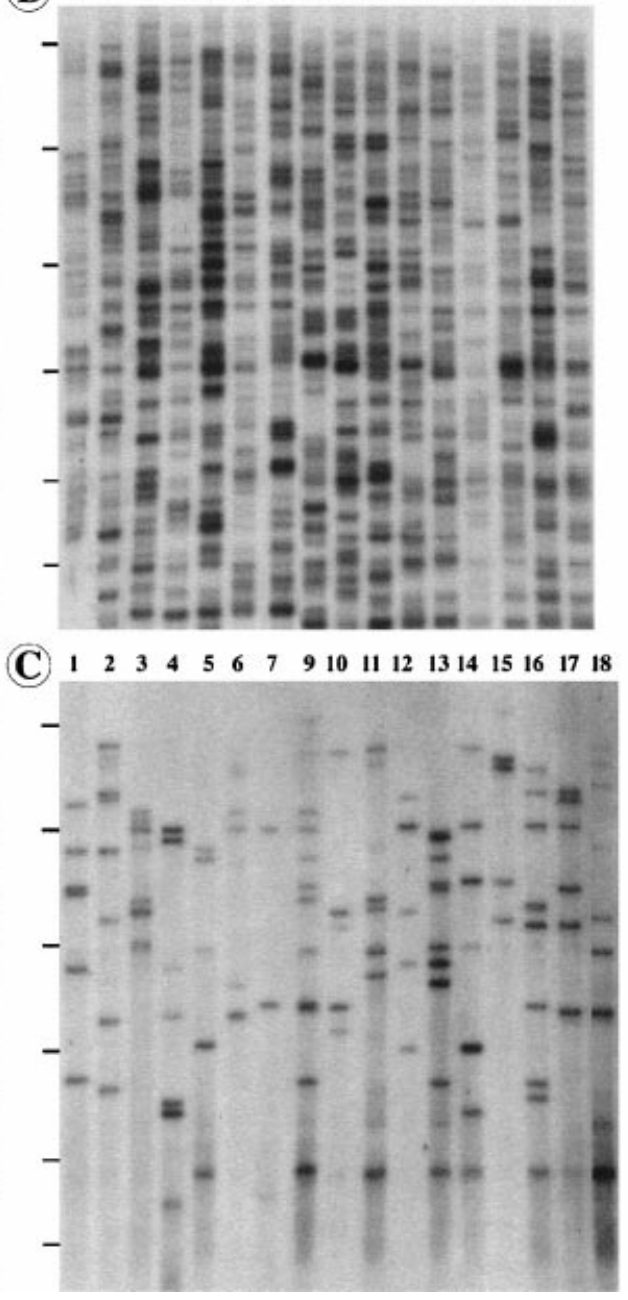

Fig. 3 Southern blots of genomic DNA from individuals of the Queimodas populations of Drosophila madeirensis and of the Chão dos Louros (1-9) and Rabaçal (10-18) populations of D. subobscura. (A) DNA digested with HindIII, transferred to filters, and probed with 412. (B) DNA digested with HindIII, and filters probed with bilbo. (C) DNA digested with EcoRI, and filters probed with gypsy. CL, Chão dos Louros; CR, Chão da Ribeira; Qu, Queimadas; Ra, Rabaçal; RF, Ribeiro Frio. 
( $F=210.9, P<0.001)$ and gypsy (the number of bands ranged from 5.9 to 8.0$)(F=141.9, P<0.001)$, but globally more bands for bilbo (the number of bands ranged from 35.8 to 36.2$)(F=42.8, P<0.001)$. In contrast to the findings in $D$. madeirensis, the Southern blot revealed no significant differences in band number between populations of $D$. subobscura $(F=1.90, P=0.15$ for $412 ; F=0.77, P=0.52$ for gypsy; $F=0.03, P=0.99$ for bilbo).

In $D$. madeirensis, the element bilbo had fewer bands on the Southern blot than insertion sites detected by in situ hybridization, whereas 412 and gypsy had more Southern bands than euchromatic insertion sites. Such data could be attributable to band co-migration in the Southern blot experiment for bilbo, and to the presence in heterochromatic regions of insertions of 412 and gypsy, which are not detected by the in situ technique, because heterochromatin is largely under-replicated in polytene chromosomes. Variation in copy number between populations of these heterochromatic bands, in addition to a higher variance in labelled insertion site number estimated by in situ hybridization, could explain the significant variation observed between populations of D. madeirensis when Southern band numbers were considered.

\section{Population structure}

The 0 and 1 matrices obtained from the different Southern blots from the TEs in D. madeirensis, were analysed by AMOVA. To ensure the accuracy of band detection, only the parts of the filters with the best band resolution were used, i.e. regions from $2.3,2.9,1.8-18.5 \mathrm{~kb}$, for 412 , gypsy and bilbo, respectively. The extended Amova of Steward \& Excoffier (1996) detected low between-population variation (2.8\% of the total variation) and very high within-population variation (97.2), calculated for all TEs simultaneously. This between-individual divergence of band profiles was reflected in the value of the $\Phi_{\mathrm{ST}}$ index, calculated from the matrix formed with the three TEs. This index was low (0.028), although it was significantly different from zero. The pairwise population estimates of $\Phi_{\mathrm{ST}}$ shown in Table 2, were analysed by multidimensional scaling. This analysis showed that the Ribeiro Frio

Table 2 Pairwise genetic distances $\left(\Phi_{\mathrm{ST}}\right)$ between populations of Drosophila madeirensis

\begin{tabular}{lllll}
\hline & $\begin{array}{l}\text { Chão dos } \\
\text { Louros }\end{array}$ & $\begin{array}{l}\text { Chão da } \\
\text { Ribeira }\end{array}$ & Queimadas & Rabaçal \\
\hline $\begin{array}{l}\text { Chão da Ribeira } \\
\text { Queimadas }\end{array}$ & $0.0153^{*}$ & & & \\
$\begin{array}{l}\text { Rabaçal } \\
\text { Ribeiro Frio }\end{array}$ & $0.0120^{*}$ & $0.0162^{*}$ & & \\
\hline
\end{tabular}

${ }^{*} P<0.05 ;$ ns, nonsignificant. population was similar to those from Queimadas and Chão dos Louros, and that these three populations could be differentiated from the Rabaçal and Chão da Ribeira populations. This reflected the distance between the populations in terms of the presence of geographical obstacles, such as mountains and deep valleys.

\section{Discussion}

The genome of the endemic species Drosophila madeirensis appears to have numerous euchromatic insertion sites of the TEs, 412, gypsy and bilbo, with a very high level of insertion polymorphism. In addition, labelling of the chromocentre and pericentromeric regions for bilbo and 412 , recalls some of the data for D. subobscura (Blesa \& Martinez-Sebastian 1997) and D. melanogaster (Charlesworth et al. 1992; Biémont et al. 1994a), which suggest that the presence of these elements is old enough in the $D$. madeirensis genome for them to have become embedded in the heterochromatin. TE copy numbers in $D$. madeirensis are even higher than in D. subobscura, its close relative, which has spread over Europe, the Middle East and North Africa, as well as the islands of the Azores, Madeira and the Canaries (Noor et al. 2000). The copy numbers of 412 and bilbo in the Madeiran populations of $D$. subobscura are even higher than those reported in continental populations (Biémont \& Cizeron 1999). These data are compatible with the observation of nearly as many copia-homologous DNA sequences in D. mauritiana, an endemic species from the island of Mauritius, as in the cosmopolitan species D. melanogaster (Csink \& McDonald 1995). Fixed copies of TEs, or at least a high frequency of TE site occupancy, are expected in species of restricted geographical range, as postulated for the 17.31 and mariner elements in D. sechellia (Capy et al. 1992; MontchampMoreau et al. 1993). We can thus conclude that the effective size of the $D$. madeirensis populations is not small enough to affect TE insertion site polymorphism or TE copy number significantly (Charlesworth \& Charlesworth 1983; Biémont et al. 1994a,b). However, the similarity in euchromatic copy numbers among the populations analysed, for both D. madeirensis and D. subobscura, strongly suggests that each of these species is represented by a single, only slightly subdivided population, in spite of the topographical extremes of Madeira, with deep valleys surrounded by high mountains. We cannot, however, entirely exclude the possibility that the similar TE copy numbers could result from similar forces (e.g. specific copy number regulatory mechanism, environment, population size) at work on the populations, and acting on the 412 , gypsy and bilbo elements analysed. It is also possible that the species $D$. madeirensis has only recently invaded the various valleys, and that there has not yet been time for marked differentiation between the populations to 
develop. If this is true, then the effective size of each subpopulation must have been large, because any inbreeding due to a small effective size or an initial bottleneck should have lead to more homogeneous individuals within the populations (Biémont et al. 1994b), which would have led to a greater between-population differentiation than is actually observed. Moreover, the fact that populations of $D$. madeirensis and those of its close relative, $D$. subobscura, displayed similar high levels of polymorphism in their TE profiles, adds strength to the hypothesis that there are large populations of each species. Although such data cannot predict what would be observed for allozymes, which have a lower mutation rate than TEs, they are in agreement with the lack of genetic differentiation found between the populations Minorca and Majorca in the Balearic Islands using both allozymes and mitochondrial DNA (Castro et al. 1999). These latter data suggest that gene flow may occur between neighbouring islands of archipelagos and between different valleys within an island, or that rapid population growth has renewed genetic diversity (Nei et al. 1987; Davies et al. 1999; Urbanelli et al. 2000). The present findings indicate that TEs, which are efficient in maintaining genetic variability within populations of Drosophila on islands, are powerful tools for determining population structuring.

\section{Acknowledgements}

We would like to thank D. Blesa and R. De Frutos for their gifts of DNA probes. We are grateful to J. Jesus and P. Andrade for capturing the flies, to C. Lœvenbruck, C. Jarrin and C. Vieira for their help, to the referees for their comments, and to M. Ghosh for correcting the English. This work was supported by the Centre National de la Recherche Scientifique (the genome programme and GDR 2157), the Ministère de La Recherche, and the Association pour la Recherche sur le Cancer (contract 5428). A.B. was supported by a grant from Fundação Calouste Gulbenkian (Lisbon).

\section{References}

Aquadro CF, Lado KM, Noon WA (1988) The rosy region of Drosophila melanogaster and Drosophila simulans. I. Contrasting levels of naturally occurring DNA restriction map variation and divergence. Genetics, 119, 875-888.

Biémont C (1994) Dynamic equilibrium between insertion and excision of $\mathrm{P}$ elements in highly inbred lines from an $\mathrm{M}^{\prime}$ strain of Drosophila melanogaster. Journal of Molecular Evolution, 39, 466-472.

Biémont C, Cizeron G (1999) Distribution of transposable elements in Drosophila Species. Genetica, 105, 43-62.

Biémont C, Lemeunier F, Garcia Guerreiro MP et al. (1994a) Population dynamic of the copia, mdg1, mdg3, gypsy, and $\mathrm{P}$ transposable elements in a natural population of Drosophila melanogaster. Genetical Research, 63, 197-212.

Biémont C, Lemeunier F, Gautier C, Garcia Guerreiro M, Aulard S, Pasyukova EG (1994b) High rate of movement of one (mdg3) out of four transposable elements in a natural population of Drosophila melanogaster. Comptes Rendus des Séances de l'Académie des Sciences, 317, 283-286.

Blesa S, Martinez-Sebastian MJ (1997) Bilbo, a non-LTR retrotransposon of Drosophila subobscura: a clue to the evolution of LINElike elements in Drosophila. Molecular Biology and Evolution, 14, 1145-1153.

Brehm A (1992) Appendix I. Photographic maps of the polytene chromosomes of D. subobscura. In: Drosophila Subobscura: Biology, Genetics and Inversion Polymorphism (ed. Krimbas CB) CRC Press, Boca Raton, FL.

Brezinsky L, Humphreys TD, Hunt JA (1992) Evolution of the transposable element $u h u$ in five species of Hawaiian Drosophila. Genetica, 86, 21-35.

Capy P, David JR, Hartl DL (1992) Evolution of the transposable element mariner in the Drosophila melanogaster species group. Genetica, 86, 37-46.

Castro JA, Ramon M, Picornell A, Moya A (1999) The genetic structure of Drosophila subobscura populations from the islands of Majorca and Minorca (Balearic Islands, Spain) based on allozymes and mitochondrial DNA. Heredity, 83, 271-279.

Charlesworth B, Charlesworth D (1983) The population dynamics of transposable elements. Genetical Research, 42, 1-27.

Charlesworth B, Lapid A, Canada D (1992) The distribution of transposable elements within and between chromosomes in a population of Drosophila melanogaster. I. Element frequencies and distribution. Genetical Research, 60, 103-114.

Csink AK, Mcdonald F (1995) Analysis of Copia sequence variation within and between Drosophila species. Molecular Biology and Evolution, 12, 83-93.

Davies N, Villablanca FX, Roderick GK (1999) Bioinvasions of the medfly Ceratitis capitata: source estimation using DNA sequences at multiple intron loci. Genetics, 153, 351-360.

Di Franco C, Pisano C, Dimitri P, Gigliotti S, Junakovic N (1989) Genomic distribution of copia-like transposable elements in somatic tissues and during development of Drosophila melanogaster. Chromosoma, 98, 402-410.

Duvernell DD, Turner B (1999) Variation and divergence of Death Valley pupfish populations at retrotransposon-defined loci. Molecular Biology and Evolution, 16, 363-371.

Excoffier L, Smouse PE, Quattro JM (1992) Analysis of molecular variance inferred from metric distances among DNA haplotypes: application to human mitochondrial DNA restriction data. Genetics, 131, 479-491.

Heslop-Harrison JS, Brandes A, Taketa S et al. (1997) The chromosomal distribution of Ty1-copia group retrotransposable elements in higher plants and their implications for genome evolution. Genetica, 100, 197-204.

Hey J (1989) The transposable portion of the genome of D. algonquin is very different from that in D. melanogaster. Molecular Biology and Evolution, 6, 66-79.

Junakovic N, Caneva R, Ballario P (1984) Genomic distribution of copia-like elements in laboratory stocks of Drosophila melanogaster. Chromosoma, 90, 378-382.

Kalendar R, Grob T, Regina M, Suoniemi A, Schulman A (1999) IRAP and REMAP: two new retrotransposon-based DNA fingerprinting techniques. Theoretical and Applied Genetics, 98, 704-711.

Kalendar R, Tanskanen J, Immonen S, Nevo E, Schulman AH (2000) Genome evolution of wild barley (Hordeum spontaneum) by BARE-1 retrotransposon dynamics in response to sharp microclimatic divergence. Proceedings of the National Academy of Sciences USA, 97, 6603-6607. 
Krimbas C, Loukas M (1984) Evolution of the 'obscura' group Drosophila species. I. Salivary chromosomes and quantitative characters in D. subobscura and two closely related species. Heredity, 53, 469-482.

Kumar A, Hirochika H (2001) Applications of retrotransposons as genetic tools in plant biology. Trends in Plant Science, 6, 127134.

Kunze-Muhl E, Muller E (1958) Weitere Untersuchungen uber die chromosomale Struktur und naturlichen Strukturtypen von Drosophila subobscura. Chromosoma, 9, 559-570.

Labrador M, Seleme MC, Fontdevila A (1998) The evolutionary history of Drosophila buzzatii. XXXIV. The distribution of the retrotransposon Osvaldo in original and colonizing populations. Molecular Biology and Evolution, 15, 1532-1547.

Labrador M, Farré M, Utzet F, Fontdevilla A (1999) Interspecific hybridization increases transposition rates of Osvado. Molecular Biology and Evolution, 16, 931-937.

Löwer R, Löwer J, Kurth R (1996) The viruses in all of us: Characteristics and biological significance of human endogenous retrovirus sequences. Proceedings of the National Academy of Sciences USA, 93, 5177-5184.

Montchamp-Moreau C, Ronsseray S, Jacques M, Lehmann M, Anxolabéhère D (1993) Distribution and conservation of sequences homologous to the 1731 retrotransposon in Drosophila. Molecular Biology and Evolution, 10, 791-803.

Nei M, Maruyama T, Chakraborty R (1987) The bottleneck effect and genetic variability in populations. Evolution, 29, 1-10.

Noor MAF, Pascual M, Smith KR (2000) Genetic variation in the spread of Drosophila subobscura from a nonequilibrium population. Evolution, 54, 696-703.

Patience C, Wilkinson DA, Weiss RA (1997) Our retroviral heritage. Trends in Genetics, 13, 116-120.

Schneider S, Roessli D, Excoffier L (2000) Arlequin, Version 2000: A Software for Population Genetics Data Analysis. Genetics and Biometry Laboratory, University of Geneva, Geneva.

Sheen F-M, Sherry ST, Risch GM, Robichaux M, Nasidze I, Stoneking M, Batzer MA, Swergold GD (2000) Reading between the LINEs: human genomic variation induced by LINE-1 retrotransposition. Genome Research, 10, 1496-1508.

Steward CN, Excoffier L (1996) Assessing population genetic structure and variability with RAPD data: application to Vaccinium macrocarpon (American Cranberry). Journal of Evolutionary Biology, 9, 153-171.

Tarchini R, Biddle P, Wineland R, Tingey S, Rafalski A (2000) The complete sequence of $340 \mathrm{~kb}$ of DNA around the rice Adh1-adh2 region reveals interrupted colinearity with maize chromosome 4. Plant Cell, 12, 381-391.

Urbanelli S, Bellini R, Carrieri M, Sallicandro P, Celli G (2000) Population structure of Aedes albopictus (Skuse): the mosquito which is colonizing mediterranean countries. Heredity, 84, 331-337.

Vasquez-Manrique RP, Hernandez M, Martinez-Sebastian MJ, de Frutos R (2000) Evolution of gypsy endogenous retrovirus in the Drosophila obscura species group. Molecular Biology and Evolution, 17, 1185-1193.

Vieira C, Lepetit D, Dumont S, Biémont C (1999) Wake up of transposable elements following Drosophila simulans worldwide colonization. Molecular Biology and Evolution, 16, 1251-1255.

Wisotzkey RG, Felger I, Hunt JA (1997) Biogeographic analysis of the $u h u$ and $L O A$ elements in the Hawaiian Drosophila. Chromosoma, 106, 465-477.

Yuki S, Inouye S, Ishimaru S, Saigo K (1986) Nucleotide sequence characterization of a Drosophila retrotransposon, 412. European Journal of Biochemistry, 158, 403-410.

This work is part of David Lepetit's doctoral thesis, which focuses on the distribution and structure of transposable elements in the species Drosophila madeirensis on the island of Madeira. This research is part of a larger project being conducted under the supervision of Christian Biémont, which is intended to evaluate the influence of transposable elements in natural populations. Pierre Fouillet is a CNRS scientist specializing in statistics and software. This work was carried out in close collaboration with Professor Antonio Brehm from the University of Madeira. 